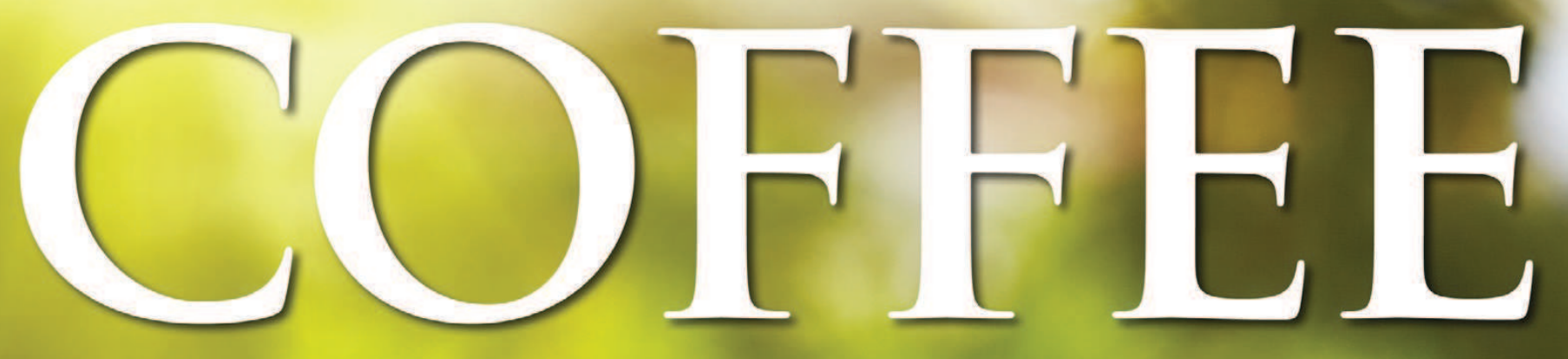

\title{
IN HEALTH AND \\ DISEASE PREVENTION
}

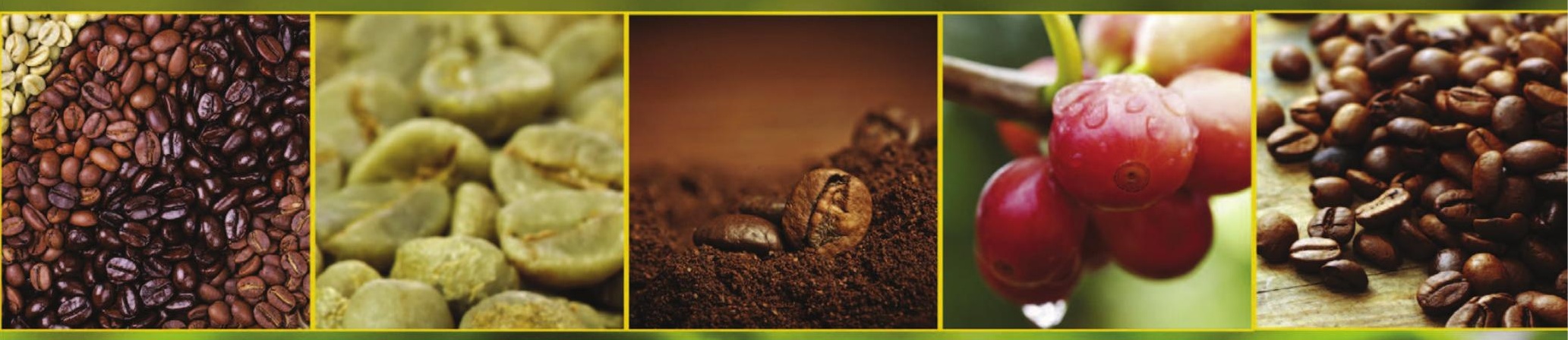

EDITED BY

VICTOR R PREEDY 


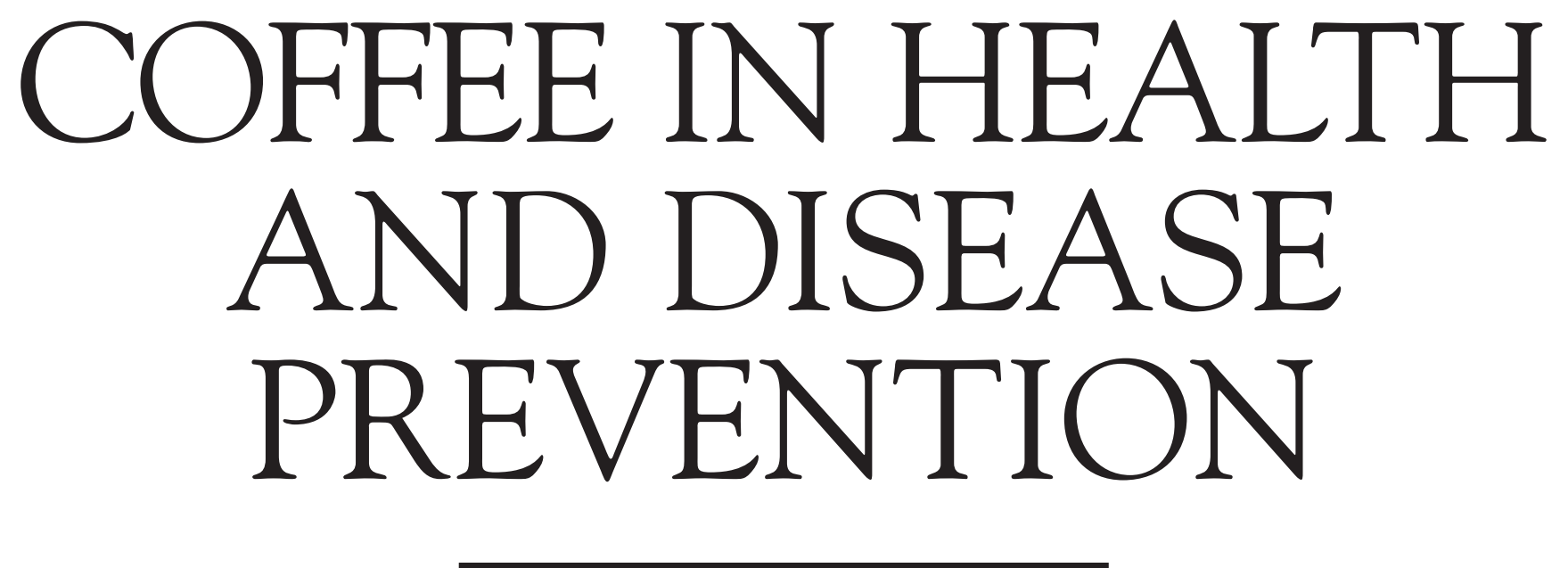

Edited by

Victor R. PREedy

Department of Nutrition and Dietetics, King's College London, London, UK

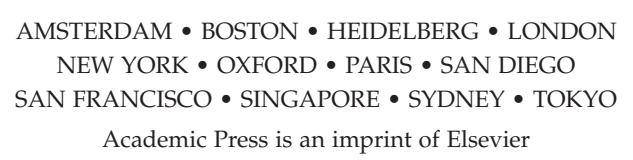


Academic Press is an imprint of Elsevier

32 Jamestown Road, London NW1 7BY, UK

525 B Street, Suite 1800, San Diego, CA 92101-4495, USA

225 Wyman Street, Waltham, MA 02451, USA

The Boulevard, Langford Lane, Kidlington, Oxford OX5 1GB, UK

Copyright ( 2015 Elsevier Inc. All rights reserved.

Medicine is an ever-changing field. Standard safety precautions must be followed, but as new research and clinical experience broaden our knowledge, changes in treatment and drug therapy may become necessary or appropriate. Readers are advised to check the most current product information provided by the manufacturer of each drug to be administered to verify the recommended dose, the method and duration of administrations, and contraindications. It is the responsibility of the treating physician, relying on experience and knowledge of the patient, to determine dosages and the best treatment for each individual patient. Neither the publisher nor the authors assume any liability for any injury and/or damage to persons or property arising from this publication.

No part of this publication may be reproduced or transmitted in any form or by any means, electronic or mechanical, including photocopying, recording, or any information storage and retrieval system, without permission in writing from the publisher. Details on how to seek permission, further information about the Publisher's permissions policies and our arrangements with organizations such as the Copyright Clearance Center and the Copyright Licensing Agency, can be found at our website: www.elsevier.com/permissions.

This book and the individual contributions contained in it are protected under copyright by the Publisher (other than as may be noted herein).

\section{Notices}

Knowledge and best practice in this field are constantly changing. As new research and experience broaden our understanding, changes in research methods, professional practices, or medical treatment may become necessary.

Practitioners and researchers must always rely on their own experience and knowledge in evaluating and using any information, methods, compounds, or experiments described herein. In using such information or methods they should be mindful of their own safety and the safety of others, including parties for whom they have a professional responsibility.

To the fullest extent of the law, neither the Publisher nor the authors, contributors, or editors, assume any liability for any injury and/or damage to persons or property as a matter of products liability, negligence or otherwise, or from any use or operation of any methods, products, instructions, or ideas contained in the material herein.

ISBN: 978-0-12-409517-5

British Library Cataloguing-in-Publication Data

A catalogue record for this book is available from the British Library

Library of Congress Cataloging-in-Publication Data

A catalog record for this book is available from the Library of Congress

For information on all Academic Press publications visit our website at http:/ / store.elsevier.com/

Typeset by TNQ Books and Journals www.tnq.co.in

Printed and bound in United States of America

$$
\begin{aligned}
& \text { Working together } \\
& \text { to grow libraries in } \\
& \begin{array}{l}
\text { Book Aid } \\
\text { International }
\end{array} \\
& \text { developing countries }
\end{aligned}
$$




\title{
24
}

\section{Factors Affecting Acrylamide Levels in Coffee Beverages}

\author{
Cristina M.D. Soares ${ }^{1, *}$, Rita C. Alves ${ }^{2,3, *}$, M. Beatriz P.P. Oliveira ${ }^{2}$ \\ ${ }^{1}$ REQUIMTE, Departamento de Química e Bioquímica, Universidade do Porto, Porto, Portugal; ${ }^{2}$ REQUIMTE, \\ Departamento de Ciências Químicas, Universidade do Porto, Porto, Portugal; ${ }^{3}$ REQUIMTE, Instituto Superior de \\ Engenharia do Porto, Instituto Politécnico do Porto, Porto, Portugal \\ *Both authors contributed equally to this work
}

\subsection{INTRODUCTION}

Thermal processing of foods (domestic or industrial) improves their organoleptic properties, preservation, and microbiological safety, inducing chemical changes and the formation of new molecules. Some of these impart positive health effects, while others are claimed to have carcinogenic and, in some cases, mutagenic properties. ${ }^{1}$ Acrylamide, one of these compounds, was discovered by Swedish researchers in $2002 .{ }^{2}$

Although free acrylamide has known toxic effects on the nervous system and on fertility, a report of the Food and Agriculture Organization of the United Nations and the World Health Organization concluded that the necessary level to observe neuropathy and effects on fertility is at least 500 times higher than the average dietary intake. ${ }^{3}$ Consequently, it was concluded that acrylamide levels in food are safe in terms of neuropathy, but raised concerns over human carcinogenicity based on known carcinogenicity in laboratory animals. ${ }^{3}$ Because of that, acrylamide has been classified as "probably carcinogenic to humans" (class 2A) by the International Agency for Research on Cancer. Although there is conflicting evidence about its potential harmfulness, the concern is due to its presence in foodstuffs usually highly consumed worldwide, as potato products (French fries, potato chips, roasted and baked potatoes), bread, or coffee. In fact, coffee has been reported as a substantial contributor to the total dietary intake of acrylamide, especially in Nordic countries, due to its high consumption. ${ }^{4}$

Precisely to acrylamide's adverse effects, the European Commission recommended that it should be monitored in foodstuffs throughout the European Union.
This monitoring should cover foodstuffs such as potato products (chips and crisps), cereals (bread, cakes, breakfast flakes, and infant cereals), and roasted coffee. ${ }^{5}$ More recently, the European Commission also recommended the comparison of acrylamide levels in food with a "check value" indicator previously defined for a range of foods. For roasted and instant coffee, the levels should not exceed $450 \mu \mathrm{g} / \mathrm{kg}$ and $900 \mu \mathrm{g} / \mathrm{kg}$, respectively. ${ }^{6}$ As a result, it became necessary to establish suitable methods for measuring acrylamide in foodstuffs, including in roasted coffee. According to the above recommendation, ${ }^{6}$ the limit of quantification of the analytical methods has been set at $30 \mu \mathrm{g} / \mathrm{kg}$ for bread and baby foods and $50 \mu \mathrm{g} / \mathrm{kg}$ for other foods, including coffee. More recently, the European Commission recommended the extension of the monitoring period for acrylamide in foodstuffs indefinitely, and increased the range of foodstuffs to be tested. ${ }^{7}$

An overview of some possible routes for acrylamide formation is presented in Figure 24.1.

\subsection{FACTORS AFFECTING ACRYLAMIDE LEVELS IN COFFEE BEVERAGES}

Coffee is generally roasted at temperatures in the range of $220-250^{\circ} \mathrm{C}$, and the time and speed of roasting play an important role on the sensorial properties, such as color, aroma, and taste. These are carefully controlled to produce a characteristic profile leading to the clear identity of the coffee product. The characteristics of the final product are also dependent on the raw material composition, on the coffee variety, and on post-harvest 


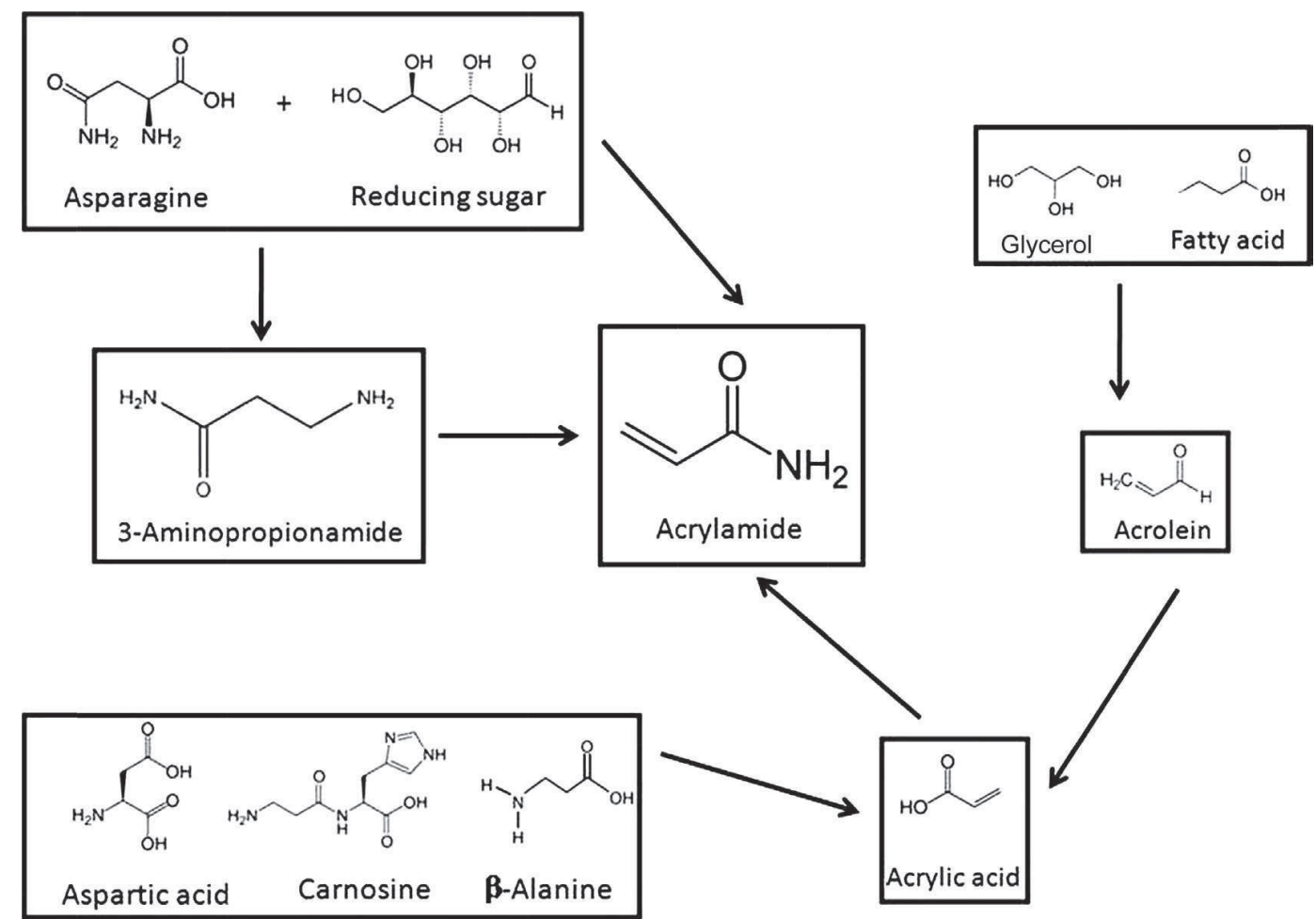

FIGURE 24.1 Possible routes for acrylamide formation in foodstuffs during thermal processing. The main route for the formation of acrylamide in foodstuffs is the Maillard reaction, initiated by the condensation of asparagine and reducing carbohydrates at temperatures above $120^{\circ} \mathrm{C}$ in dehydrated conditions. Recently, 3-aminopropionamide (3-APA) was suggested to be an intermediate in the formation of acrylamide in foods. Some studies showed that acrylamide can be formed easily from 3-APA, even under aqueous conditions and with no reducing sugars in the system. Acrolein has a resemblant structure with acrylamide and can be formed by transformation of lipids or degradation of other compounds and after several chemical transformations (such as reaction with ammonia liberated from amino acids) can be converted (or a derivative of it) into acrylamide. Proteins and/or amino acids can, after a series of transformations, such as hydrolyses, rearrangements, and decarboxylations, eventually lead to acrylamide.

processing, and the intake is also dependent on the way the coffee brew is prepared. ${ }^{8}$ Figure 24.2 presents the factors affecting the acrylamide quantity in coffee beverages, which will be more thoroughly discussed in the next sections.

\subsubsection{Influence of Green Coffee}

The two coffee species of higher commercial importance are Coffea arabica and Coffea canephora var. robusta. Arabica and robusta coffees account for $\sim 64 \%$ and $~ 35 \%$ of the world's coffee production, respectively. Both species are chemically distinct and characterized by different levels of minerals, volatile substances, chlorogenic acids, and caffeine. Their different chemical composition leads to distinctively different flavor profiles after roasting. Usually, the quality of the coffee beverage is dependent on the proportion of both varieties in the blend, arabica being a higher value product. ${ }^{8}$

The main precursors of acrylamide in coffee seem to be sucrose and asparagine. The concentration of sucrose in green coffee is usually lower in robusta and higher in arabica varieties, while the concentration of free asparagine in robusta coffees is normally higher than in arabica ones. ${ }^{9}$ Nevertheless, this may vary significantly due to cultivation practices and processing.

The post-harvest processing of green beans includes a series of steps to provide a stable product for exportation. Three main procedures are known: the dry method ("natural"), the wet process ("washed"), and the "semiwashed" one. By the former, the cherries are dried, usually in the sun, and afterward mechanically dehusked. In the washed process, the fresh mature cherries are depulped, fermented (decomposition of mucilage remains), washed, and dried. This method is essentially used for arabica coffees and for some high quality robusta cultivars. In the third procedure, also known as "natural depulped," the fruits are depulped and directly dried without being subjected to any fermentation step. ${ }^{8}$

The type of post-harvest coffee processing determines the quality of the corresponding green beans. But, the main distinction between the chemical composition of washed and natural coffee is the soluble solids content, which is higher in the case of natural coffee. Natural depulped 


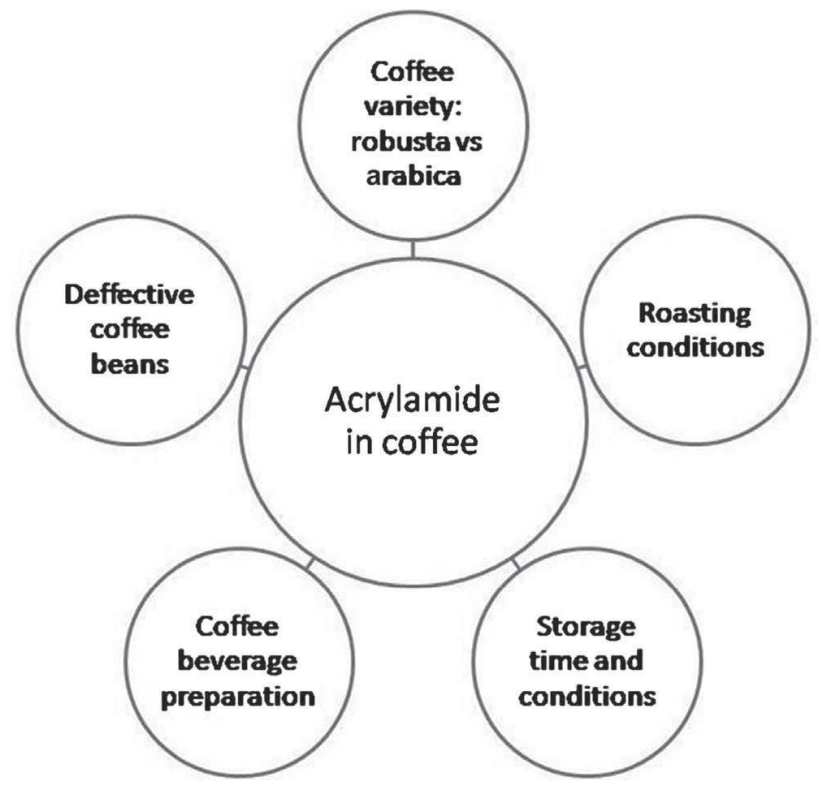

FIGURE 24.2 Main factors affecting acrylamide levels in coffee beverages. The figure shows the main factors that affect acrylamide contents in coffee: coffee variety (robusta coffee contains higher levels of acrylamide than arabica, probably due to a higher amount of free asparagine in raw beans); roasting conditions (since acrylamide is formed in the early stages of roasting but its content decreases with increasing temperature and time of roast); storage (acrylamide is not stable in commercial coffee (beans and ground) stored in its original container); beverage preparation (which affects acrylamide extraction); and defective coffee beans (in particular immature ones that contain higher amounts of free asparagine).

beans present intermediate characteristics. ${ }^{10}$ Furthermore, specific and highly low molecular flavor precursors, i.e., carbohydrates $^{11}$ and free amino acids, ${ }^{12}$ have a different profile in raw beans processed by distinct ways. Indeed, the chemical, biochemical, and physiological alterations that occur during beans processing can result in variations of the quality and quantity of flavor and aroma precursors.

Asparagine amount in the raw material seems to be a limiting factor for the acrylamide formation in coffee. In fact, the quantity of acrylamide in roasted coffee is usually higher in robusta than in arabica coffees but, regarding the precursors, a weak correlation between acrylamide and asparagine was observed, and no correlation with reducing sugars was found. ${ }^{13}$ According to the European Union Commission database, roasted coffee finished products have a median acrylamide level of 265-290 $\mu \mathrm{g}$ / $\mathrm{kg}$. Even when considering that the final roast coffee levels are only $\sim 10 \%$ of the maximum acrylamide level, it has to be concluded that only a minor portion of the asparagine in the green coffee $(0.2-1 \mathrm{~g} / \mathrm{kg})$ contributes to acrylamide. Both the low yield of the asparagine/acrylamide reaction and the significant reduction of acrylamide content during the final stages of roasting may be the reasons why the correlation between asparagine and acrylamide in coffee is less prominent than in other foods. ${ }^{14}$
A factor that could also contribute to relatively higher acrylamide levels in coffee is the number of defective beans used in production. Defective coffee beans, in particular immature ones, contain significantly higher amounts of free asparagine ( $>2$-fold) versus mature beans. ${ }^{14}$ Also, a recent work showed that the peeling of immature fruits allows a reduction in the levels of asparagine, ${ }^{15}$ which can represent a form to reduce the formation of acrylamide in coffee.

\subsubsection{Influence of Roasting Conditions}

Acrylamide levels in roasted coffee are determined by concomitant formation and reduction reactions during roasting. ${ }^{16}$ Acrylamide formation is dominant at the beginning of the roasting cycle, leading to increased levels at this stage $(>7 \mathrm{mg} / \mathrm{kg})$, which decrease quickly toward the end of the roasting cycle due to higher rates of degradation reactions. ${ }^{16}$

Kinetic models and spiking experiments with isotope-labeled acrylamide have revealed that $>95 \%$ of acrylamide is degraded during roasting. Therefore, light roasted coffees contain relatively higher amounts of acrylamide than very dark roasted beans. ${ }^{16}$

The increase of roasting time leads to the degradation of acrylamide but also to the formation of undesirable off-flavor compounds. Therefore, the optimization of the roasting conditions with respect to a reduction of the acrylamide formation and maintenance of the product quality have not been yet performed. ${ }^{17}$ Because coffee is a product with very particular quality attributes, it seems that there are not many options currently available for mitigation of acrylamide during roasting. As aroma is a result of this thermal process, and related to the chemical composition of the raw material, every change in the roasting conditions leads to a final product with different characteristics. ${ }^{18}$ The importance of the roasting process for flavor and color and the relatively narrow range for commercial products make mitigation for coffee particularly complicated. Indeed, darker roasting as a potential option to reduce acrylamide could potentially generate other undesirable compounds and will definitively affect the taste and aroma of the batch. Consequently, no practical solutions are available that would reduce acrylamide levels and concomitantly retain the quality characteristics of coffee, since the roasting step cannot be fundamentally changed.

\subsubsection{Influence of Storage}

Several research groups have reported consistent data showing that acrylamide is not stable in commercial coffee (beans and ground) stored in its original container. ${ }^{13,19-21}$ Losses of $40-60 \%$ have been reported in coffees stored at room temperature over a period of 6-12 months. ${ }^{20}$ Hoenicke and Gaterman ${ }^{21}$ observed a reduction of $30 \%$ 


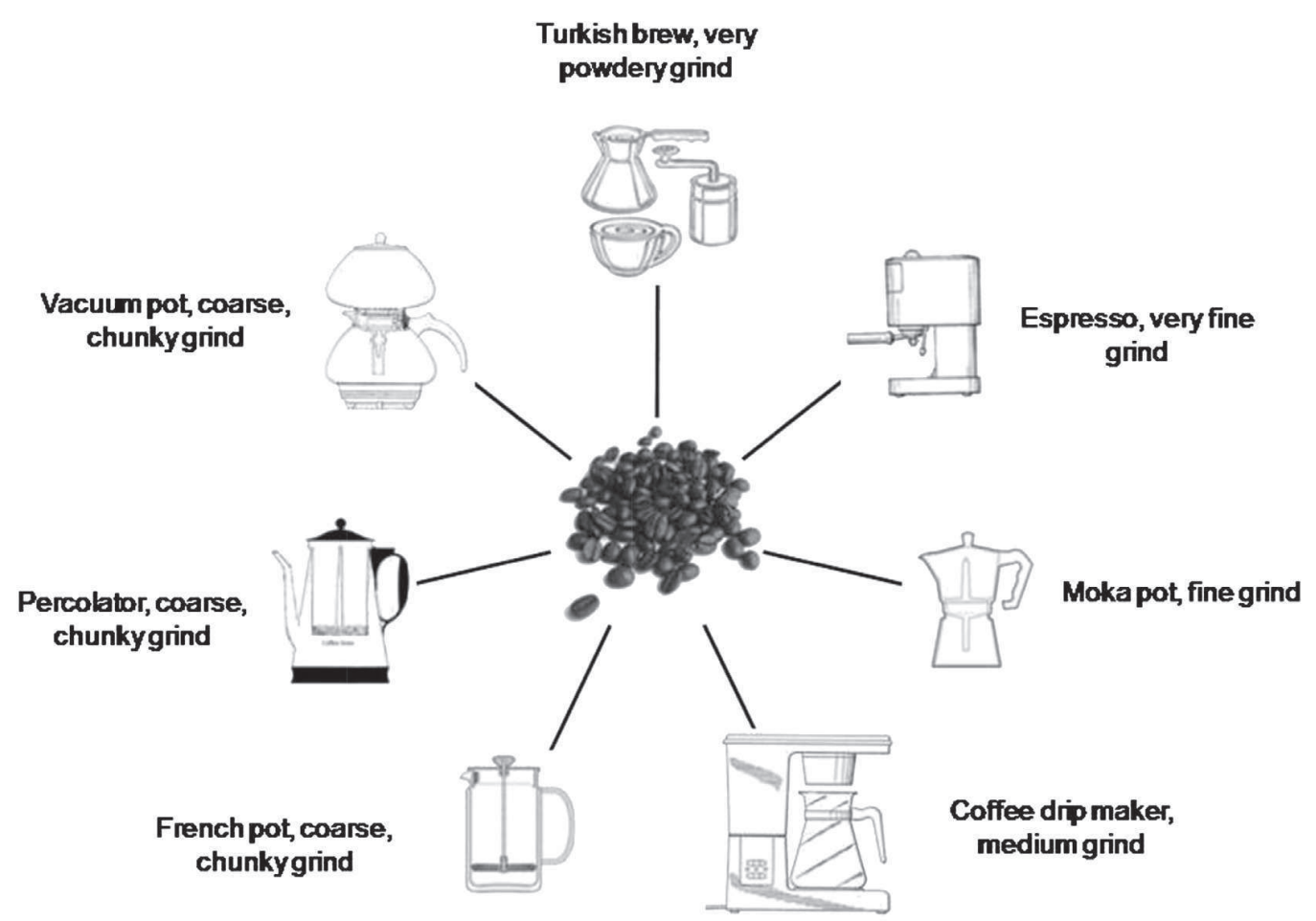

FIGURE 24.3 Examples of coffee brewing techniques and the respective grinding grades. Coffee brews are prepared using a certain volume of water (boiled, under pressure...) and a defined amount of coffee powder. The optimal grinding degree varies with the coffee brewing preparation. This figure show some examples of brew techniques and the corresponding finest grinding grades to prepare coffee beverages.

after a 3-month storage period at $10-12{ }^{\circ} \mathrm{C}$. In another study, ${ }^{13}$ the acrylamide reduction in vacuum-packed coffee was measured over 12 months at four different temperatures $\left(-18,+4\right.$, ambient, and $\left.+37^{\circ} \mathrm{C}\right)$. The rate of acrylamide depletion was distinctly correlated to the temperature; i.e., the highest rates of reduction were recorded at $37^{\circ} \mathrm{C}$ ( $>7$-fold reduction in acrylamide level after 6 months of storage time versus initial concentration).

\subsubsection{Influence of Coffee Beverage Preparation}

Coffee is usually pictured as beans, either green or roasted, but, in order to be consumed as food, it is necessary to transform the seed into a powder (using a grinder or coffee mill), a process commonly known as grinding. The main objective of this procedure is to increase the specific extraction surface, or rather, to increase the extent of the interface between water and the solid per unit weight of coffee, so as to facilitate the transfer of soluble and emulsifiable substances into the brew. Each time a solid body is broken up, additional surface is generated that comes into contact with the surrounding environment, in this case the extraction water. ${ }^{22}$

Acrylamide is highly soluble in water, ${ }^{19}$ what makes it easily extractable to the coffee beverage during its preparation. Nevertheless, the type of percolation (including preparation method and coffee/water ratio), as well as the blend composition and its roast degree, will significantly influence the acrylamide amount present in the final beverage. ${ }^{23}$ Many ways to make coffee brews are known, usually based on three different processes: decoction (boiled, Turkish, vacuum, and percolation), infusion (filter or coffee drip and napoletana), and pressure (press-pot or French press, moka, and espresso coffee). Most of them are linked to local traditions and are therefore better known by their geographical denomination than by the description of the method itself. ${ }^{24}$ In Figure 24.3, a representation of the brew technique and the corresponding grinding grade to prepare different coffee beverages is presented.

Decoction occurs when a partially soluble solid is kept in contact with a given amount of water, at an appropriate temperature, for a considerable amount of time, while allowing the concentration of solubles in the liquid to increase throughout the operation. The beverage concentration (strength) increases with the time allowed for contact, before the grounds are separated from the liquid, also due to hydrolysis of the insoluble part of the former. Higher temperature favors, of course, higher extraction yields and rates. ${ }^{24}$

In turn, infusion can be described as a flow of hot water through a bed of partially soluble material, allowing just a short contact time to every elementary volume of clean liquid. Due to the shorter contact time of this procedure, infused coffee beverages are generally sensorily described as milder than the decocted ones. ${ }^{24}$ 
TABLE 24.1 Acrylamide Levels in Common Coffee Beverages

\begin{tabular}{lll}
\hline Coffee Brew & Acrylamide Levels $(\boldsymbol{\mu g} / \mathbf{l})$ & References \\
\hline Turkish coffee & $29.0-75.0^{\mathrm{a}}$ & 25 \\
Espresso & $11.0-36.0$ & 26 \\
Moka coffee & 16.6 & 27 \\
Filter coffee & $6.0-16.0$ & 19 \\
& 8.0 & 28 \\
French press cafetiere & 9.0 & 28 \\
\hline
\end{tabular}

${ }^{a} \mu g / k g$.

In general, acrylamide levels in common coffee beverages (as plunger pot and filtered coffee) range between 2 and $25 \mu \mathrm{g} / 1{ }^{4,19}$ In Table 24.1 acrylamide levels for different coffee beverages prepared from different brewing techniques are presented.

Comparatively with other coffee beverages, the brewing process to prepare an espresso extracts acrylamide incompletely due to the short contact time between coffee and water. ${ }^{13}$ This brew is prepared by a special brewing technique in which a limited amount $(20-50 \mathrm{ml})$ of hot water under high pressure $\left(9 \pm 2 \mathrm{~atm}, 90 \pm 5^{\circ} \mathrm{C}\right)$ is percolated in a very short time $(30 \pm 5 \mathrm{~s})$ through a ground coffee cake $(6.5 \pm 1.5 \mathrm{~g})$. The result is a concentrated and intensely flavored brew covered by a dense foam layer, which should be tasted at the exact moment of extraction. ${ }^{23}$ This particular type of beverage is highly appreciated in some European countries like Italy, Portugal, and France, but its consumption is increasing worldwide.

Although acrylamide is incompletely extracted during espresso coffee preparation, the final concentration of this brew is usually higher than other coffee beverages due to the higher coffee/water ratio used to prepare it (from $6.5 \mathrm{~g} / 20 \mathrm{ml}$ to $6.5 \mathrm{~g} / 70 \mathrm{ml}$ ). Indeed, acrylamide levels of $0.32-1.76 \mu \mathrm{g} / \mathrm{cup}(30 \mathrm{ml})$, corresponding to concentrations of $10.7-58.5 \mu \mathrm{g} / 1$, are described in literature for standard espresso coffees. ${ }^{26,29}$ Recently, coffee capsules have emerged as a simple and easy way to produce espresso coffee in adapted machines. The convenience of preparation and the consistency of brew quality are very appreciated by consumers. Concerning acrylamide levels, Alves et al. ${ }^{29}$ found no significant differences between these types of espresso coffees (1.00-1.66 $\mu \mathrm{g} /$ cup $(30 \mathrm{ml})$ or $33.4-55.3 \mu \mathrm{g} / \mathrm{l})$ and the standard ones. Also, similar acrylamide contents have been described for decaffeinated espresso coffees (0.74-1.49 $\mu \mathrm{g} / \mathrm{cup}$ $(30 \mathrm{ml})$ or $24.8-49.5 \mu \mathrm{g} / \mathrm{l})$ suggesting that the decaffeination process does not influence acrylamide precursors (reducing sugars and asparagine) in green coffee beans.

Concerning the composition of the coffee blend used to prepare the beverage, the amount of arabica versus robusta species highly influences the acrylamide content. For the same roast degree, brews prepared with only robusta coffee contain approximately double amounts of this compound

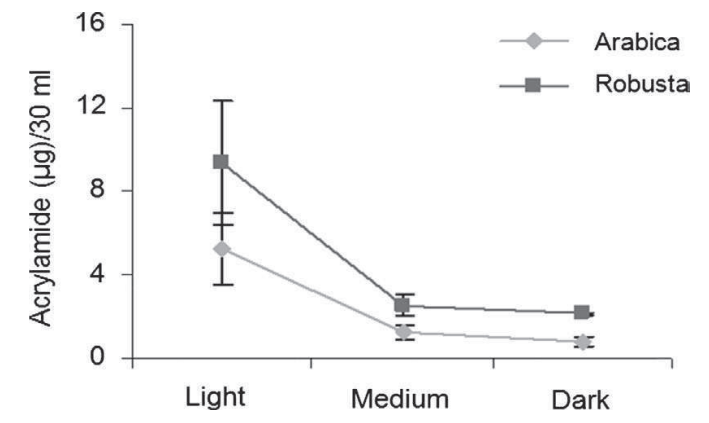

FIGURE 24.4 Relation between acrylamide levels ( $\mu \mathrm{g})$ of espresso coffees $(30 \mathrm{ml}$ per cup) and the roast degree of beans used to prepare the beverages (light, medium, and dark). This figure shows that acrylamide content of espresso coffee is higher when the brew is prepared with light roasted beans. This value tend to decrease for higher roast degrees. For the same roast degree, acrylamide content is higher in the beverages prepared with $100 \%$ robusta coffee, comparatively with those prepared only with arabica coffee.

per cup (1.71-2.92 $\mu \mathrm{g} / \mathrm{cup}(30 \mathrm{ml})$ ) of those prepared with only arabica species $(0.87$ and $1.52 \mu \mathrm{g} / \mathrm{cup}(30 \mathrm{ml}))$, as can be seen in Figure 24.4. In turn, no significant differences were found between espresso coffees prepared with arabica beans subjected to different post-harvest procedures. ${ }^{29}$

Because acrylamide is formed during the early stages of coffee roast and then its content tend to decrease, ${ }^{16,29}$ the roast degree of the coffee blend from which the brews are prepared will affect the acrylamide amount ingested by consumers. Accordingly, an average decrease of 25\% was found when medium roasted beverages were compared with their dark roasted counterparts. ${ }^{29}$ However, although coffee species and roasting degree affect the acrylamide content of the brew, they do not seem to influence acrylamide extractability ( $~ 80 \%$, for standard espresso coffees $(30 \mathrm{ml})$, and $100 \%$ for other beverages). ${ }^{13,29}$ As discussed, espresso percolation incompletely extracts acrylamide from ground coffee. Nevertheless, extending the time of extraction (and consequently increasing the volume of the brew from $20 \mathrm{ml}$ (short) to $70 \mathrm{ml}$ (long)), it was possible to increase acrylamide extractability from $\sim 60 \%$ to $\sim 99 \%$, respectively (Figure 24.5). In turn, although the final content of acrylamide increases with volume, the brew concentration simultaneously decreases due to a reduction in the coffee/water ratio: from 108.2 to $50.1 \mu \mathrm{g} / 1$ (robusta) and from 56.3 to $24.2 \mu \mathrm{g} / 1$ (arabica).

Referring to the acrylamide intake, it will obviously depend on the type and amount of beverage consumed. While espresso coffee is, generally, a very small beverage, greater volumes per cup of other coffee beverages are usually consumed. For example, a cup of filter coffee may achieve $200 \mathrm{ml}$, since it is considered a light brew. ${ }^{23}$ Therefore, acrylamide intake through coffee beverages will essentially depend on the consumption habits (type, strength, and volume of beverage, together with intake frequency), factors that are influenced by cultural and personal preferences of consumers. 


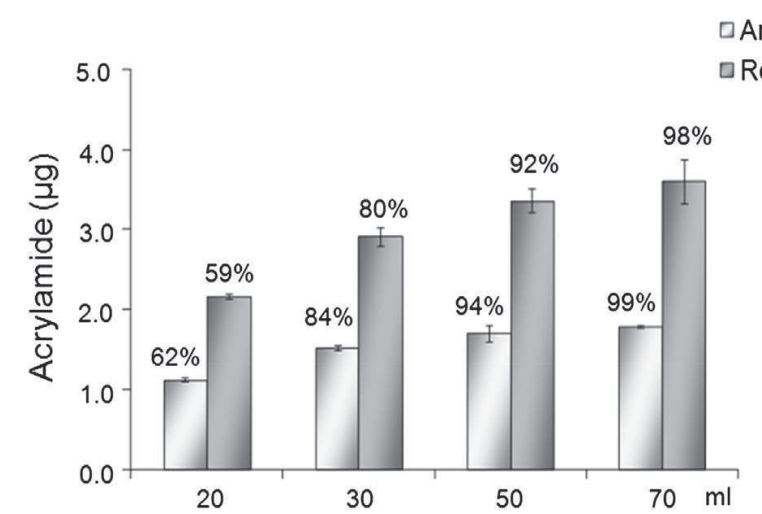

FIGURE 24.5 Influence of espresso coffee volume on acrylamide extractability. This figure shows the increase of acrylamide content of espresso coffee with the volume of the brew due to a higher contact time of the water with the coffee cake, leading to an increasing extractability of the compound. Adapted from Ref. 29.

\subsection{REDUCTION OF ACRYLAMIDE IN COFFEE PRODUCTS}

An option to reduce the amount of acrylamide ingested through coffee beverages is to select commercial blends with higher arabica percentages and darker degrees of roasting and, simultaneously, prefer shorter brews instead of long ones. ${ }^{30}$ Nevertheless, deeper roasting as a potential choice to reduce acrylamide could generate other undesirable compounds and negatively impact the sensory properties of the product. Consequently, no applicable solutions are today in practice that would reduce acrylamide levels in beans and concomitantly retain the quality characteristics of coffee, because the roasting step cannot be thoroughly changed.

There is little that can be done from a technological point of view to reduce the levels of acrylamide in coffee beans. One potential strategy for diminishing acrylamide levels is to reduce either the sugar or the asparagine content. In dough products, this can be done by introducing an enzyme that reduces the level of asparagine, but it is not attainable in the case of coffee because the reactants are located basically inside the coffee bean and it is very difficult to reach them from the outside. Several patents that describe methods to reduce acrylamide levels in food products have been reported since the announcement of acrylamide in foods and a few include the application of asparaginase as a reduction measure. A patent for the use of the asparaginase in coffee can also be consulted ${ }^{31}$ but the major hindrance is the transfer of the intact and active enzyme to the substrate. Some options like predrying the green beans to facilitate uptake of an aqueous enzyme solution, opening the pores of the beans by steam treatment or treatment under vacuum, etc., were suggested. Estimation of the degree of reduction that these procedures may provide is in the region of a 10-30\%

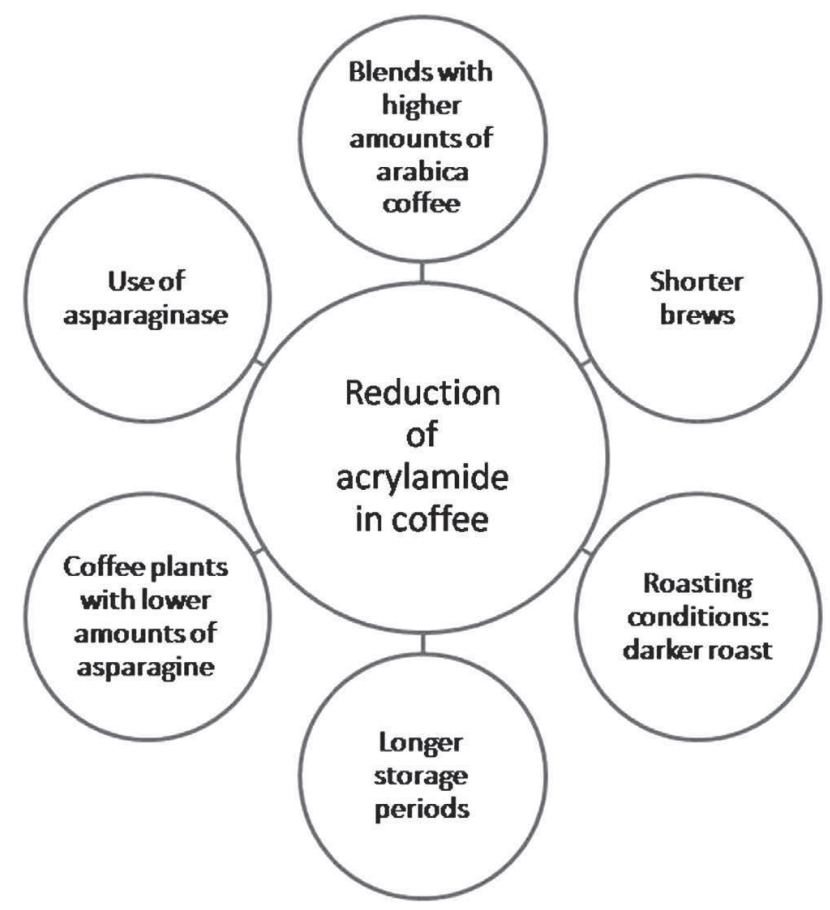

FIGURE 24.6 Possible options for reducing the acrylamide amounts in coffee beverages. This figure suggests some ways to reduce acrylamide contents in coffee beverages, namely by selecting commercial blends with higher arabica percentages and darker degrees of roasting, subjected to longer storage periods, and, simultaneously, prefer shorter brews instead of long ones. The use of asparagine and breeding plants with low asparagine levels are two procedures that are still under investigation.

reduction, but it must be taken into account the impact on the organoleptic properties of the roasted coffee. Moreover, the effect of a Maillard reactant removal like asparagine, which contributes to the formation of flavor/aroma compounds, also needs to be determined. It should be stressed that coffee is usually described as a pure product without any additives and if an enzyme is added to the beans, coffee would lose this important classification. ${ }^{17}$

Another option would be to change the roasting conditions, as was already done to some extent in potato products during frying, but this is not an appropriate strategy for coffee. Coffee is rich in antioxidants, like melanoidins, formed during roasting, ${ }^{17,23}$ but also acrylamide is formed as a consequence of the Maillard reaction and any attempt to inhibit this reaction as a possible expedient to minimize acrylamide formation could reduce the antioxidant capacity of the brew, ${ }^{32}$ as already observed in cookies by Summa et al. ${ }^{33}$ In addition, changing roasting conditions could create products that would not be accepted by the consumers. Nevertheless, different solutions are being studied based on agronomy and genetics that could result in coffee plants with low asparagine levels. Figure 24.6 presents some possible methods under study to reduce the formation of acrylamide in coffee. 


\subsection{CONCLUSION}

Acrylamide is a heat-generated food toxicant formed via the Maillard reaction between asparagine and reducing sugars. In coffee, it is formed during the early stages of roasting, but its content decreases with increasing temperature and time of roast. For the same roast degree, robusta coffee contains a higher acrylamide level than arabica, probably due to a higher initial amount of free asparagine in those beans. The acrylamide intake from coffee is influenced by several factors, namely, the coffee blend, roast degree, time and conditions of storage, and the type of percolation used to prepare the beverage.

To reduce the amount of acrylamide ingested through coffee beverages, the only suggestion available so far is to select commercial blends with higher arabica percentages and darker degrees of roasting and, simultaneously, prefer shorter brews instead of long ones, but this will obviously depend on the consumers' preferences. Nevertheless, deeper roasting as a potential choice to reduce acrylamide could generate other undesirable compounds and negatively impact the sensory properties of the product. Consequently, no applicable solutions are in practice today that would reduce acrylamide levels in beans and concomitantly retain the quality characteristics of coffee, because the roasting step cannot be thoroughly changed. There is little that can be done from a technological point of view to reduce the high levels of acrylamide in coffee beans. However, other solutions based in agronomy like breeding plants with low asparagine levels could eventually be done.

\subsection{SUMMARY POINTS}

- Acrylamide is a heat-generated food toxicant.

- Acrylamide is formed via the Maillard reaction between asparagine and reducing sugars.

- Acrylamide levels are high in the early stages of roast and then tend to decrease.

- For similar roast degrees, robusta coffee contain higher acrylamide levels than arabica.

- The way the coffee beverage is prepared influences its acrylamide content.

- According to EU recommendations, acrylamide should be continuously monitored.

\section{Acknowledgments}

This work received financial support from the European Union (FEDER/COMPETE) and National Funds (Fundação para a Ciência e a Tecnologia (FCT)) through project Pest-C/EQB/LA0006/2013; and from FEDER funds, under the framework of QREN through Project NORTE07-0124-FEDER-000069-CIÊNCIA DO ALIMENTO. C. Soares and R. C.
Alves are grateful to FCT for their PhD (SFRH/BD/39360/2007) and postdoctoral grants (SFRH/BPD/68883/2010), respectively, financed by POPH-QREN and subsidized by FSE and MCTES.

\section{References}

1. Studer A, Blank I, Stadler RH. Thermal processing in foodstuffs and potential strategies of control. Czech J Food Sci 2004;22:1-10.

2. Tareke E, Rydberg P, Karlsson P, Eriksson S, Törnqvist M. Analysis of acrylamide, a carcinogen formed in heated foodstuffs. J Agric Food Chem 2002;50:4998-5006.

3. FAO/WHO, Consultation on the health implications of acrylamide in food. Geneva; June 25-27, 2002. Summary Report (PDF) [accessed on 15.08.13].

4. Dybing E, Farmer P, Andersen M, Fennell T, Lalljie S, Müller D, et al. Human exposure and internal dose assessments of acrylamide in food. Food Chem Toxicol 2005;43:365-410.

5. Commission recommendation of 3 May 2007 on the monitoring of acrylamide levels in food (2007/331/EC). Off J Eur Union L May 12, 2007;123(33).

6. Commission recommendation of 10.1.2011 on investigations into the levels of acrylamide in food. http:/ / ec.europa.eu/food/food /chemicalsafety/contaminants/recommendation_10012011_acryl amide_food_pl.pdf [accessed on 15.08.13].

7. Commission recommendation of 2 June 2010 on the monitoring of acrylamide levels in food (2010/307/EU). Off J Eur Union L June 3, 2010;137(4).

8. Alves RC, Oliveira MBPP, Casal S. Coffee authenticity. In: Oliveira MBPP, Mafra I, Amaral JS, editors. Current topics on food authentication. (Kerala, India): Transworld Research Network; 2011. pp. 57-72.

9. Murkovic M, Derler K. Analysis of amino acids and carbohydrates in green coffee. J Biochem Biophys Methods 2006;69:25-32.

10. Bee S, Brando CHJ, Brumen G, Carvalhaes N, Kölling-Speer I, Speer $\mathrm{K}$, et al. The raw bean. In: Illy A, Viani R, editors. Espresso coffee: the science of quality. 2nd ed. London (UK): Academic Press; 2005.

11. Knopp SE, Bytof G, Selmar D. Influence of processing on the content of sugars in green Arabica coffee beans. Eur Food Res Technol 2006;223:195-201.

12. Bytof G, Knopp SE, Schieberle P, Teutsch I, Selmar D. Influence of processing on the generation of $\gamma$-aminobutyric acid in green coffee beans. Eur Food Res Technol 2005;220:245-50.

13. Lantz I, Ternite R, Wilkens J, Hoenicke K, Guenther H, van der Stegen G. Studies on acrylamide levels in roastings, storage and brewing of coffee. Mol Nutr Food Res 2006;50:1039-46.

14. Mazzafera P. Chemical composition of defective coffee beans. Food Chem 1999;64:547-54.

15. Dias EC, Borém FM, Pereira RGFA, Guerreiro MC. Amino acid profiles in unripe Arabica coffee fruits processed using wet and dry methods. Eur Food Res Technol 2012;234:25-32.

16. Taeymans D, Wood J, Ashby P, Blank I, Studer A, Stadler RH, et al. A review of acrylamide: an industry perspective on research, analysis, formation, and control. Crit Rev Food Sci Nutr 2004;44:323-47.

17. Guenther H, Anklam E, Wenzl T, Stadler RH. Acrylamide in coffee: review of progress in analysis, formation and level reduction. Food Addit Contam 2007;24:60-70.

18. Bagdonaite K, Derler K, Murkovic M. Determination of acrylamide during roasting of coffee. J Agric Food Chem 2008;56:6081-6.

19. Andrzejewski D, Roach JA, Gay ML, Musser SM. Analysis of coffee for the presence of acrylamide by LC-MS/MS. J Agric Food Chem 2004;52:1996-2002.

20. Delatour T, Périsset A, Goldmann T, Riediker S, Stadler RH. Improved sample preparation to determine acrylamide in difficult matrixes such as chocolate powder, cocoa, and coffee by liquid chromatography tandem mass spectroscopy. I Agric Food Chem 2004;52:4625-31. 
21. Hoenicke K, Gatermann R. Studies on the stability of acrylamide in food during storage. J AOAC Int 2005;88:268-73.

22. Petracco M. Grinding. In: Illy A, Viani R, editors. Espresso coffee: the science of quality. 2nd ed. London (UK): Academic Press; 2005.

23. Alves RC, Casal S, Oliveira MBPP. Factors influencing the norharman and harman contents in espresso coffee. J Agric Food Chem 2007:55:1832-8.

24. Petracco M. Technology IV: beverage preparation: brewing trends for the new millennium. In: Clarke RJ, Vitzthum OG, editors. Coffee, recent developments. Oxford (UK): Blackwell Science, Ltd; 2001.

25. Senyuva HZ, Gökmen V. Study of acrylamide in coffee using an improved liquid chromatography mass spectrometry method: investigation of colour changes and acrylamide formation in coffee during roasting. Food Addit Contam 2005;22:214-20.

26. Soares C, Cunha S, Fernandes J. Determination of acrylamide in coffee and coffee products by GC-MS using an improved SPE clean-up. Food Addit Contam 2006;23:1276-82.

27. Sagratini G, Fabbri A, Marucci G, Ricciutelli M, Vittori S, Ammendola S. HPLC-MS validation of QualisaFoo biosensor kit for costeffective control of acrylamide levels in Italian coffee. Food Control 2007;18:1267-71.
28. Granby K, Fagt S. Analysis of acrylamide in coffee and dietary exposure to acrylamide from coffee. Anal Chim Acta 2004;520: $177-82$.

29. Alves RC, Soares C, Casal S, Fernandes J, Oliveira MBPP. Acrylamide in espresso coffee: influence of species, roast degree and brew length. Food Chem 2010;119:929-34.

30. Stadler RH, Scholz G. Acrylamide: an update on current knowledge in analysis, levels in food, mechanisms of formation, and potential strategies of control. Nutr Rev 2004;62:449-67.

31. Bunke PR, Dria GJ, Gutwein RW, Howie JK, Lin PYT, Schafermeyer RG, et al. Method for reduction of acrylamide in roasted coffee beans, roasted coffee beans having reduced levels of acrylamide, and article of commerce. US 7220440 B2; 2007. https: / /www.google.com/patents/ US7220440 [accessed on 15.08.13].

32. Summa CA, De La Calle B, Brohee M, Stadler RH, Aklam E. Impact of the roasting degree of coffee on the in vitro radical scavenging capacity and content of acrylamide. LWT Food Sci Technol 2007;40:1849-54.

33. Summa C, Wenzl T, Brohee M, De La Calle B, Anklam E. Investigation of the correlation of the acrylamide content and the antioxidant activity of model cookies. J Agric Food Chem 2006;54:853-9. 